\section{Hiperplasia nodular focal en mujer joven}

\section{Sr. Director:}

La hiperplasia nodular focal (HNF) es una lesión hepática benigna infrecuente, de etiología desconocida, que afecta especialmente a niños (representando en esta edad el $0,02 \%$ de todos los tumores) y mujeres jóvenes $(1,2)$. Su origen reside en una reacción del parénquima hepático a una anomalía vascular preexistente; se cree que la activación de células progenitoras indiferenciadas por un flujo arterial localmente aumentado podría ser la causante de la hiperplasia $(3,4)$. Presentamos el caso de una paciente en la que se descubrió una HNF de forma casual.

Se trata de una mujer de 19 años de edad con antecedente de infecciones urinarias recurrentes desde los 3 años y reflujo vésico-ureteral grado I tras la resección parcial de la uretra. Durante un ingreso por una pielonefritis por Escherichia coli, se realizó una ecografía abdominal, hallándose una lesión focal en el segmento 2 del lóbulo hepático izquierdo, hipervascular, de 4,1 x $6,7 \mathrm{~cm}$. La paciente refería digestiones pesadas como único dato clínico reseñable. A la exploración destacaba una tensión arterial de $80 / 50 \mathrm{mmHg}$ y un hábito asténico. Una tomografía computerizada (TC) confirmó la existencia de dicha masa, discretamente hipodensa sin contraste intravenoso, hipervascular en la fase arterial tras inyectar contraste (Fig. 1) e isodensa en la fase venosa. Las pruebas de laboratorio, incluyendo las enzimas hepáticas y los marcadores CEA, CA 19.9, CA 125, beta-HCG y alfafetoproteína, fueron normales.

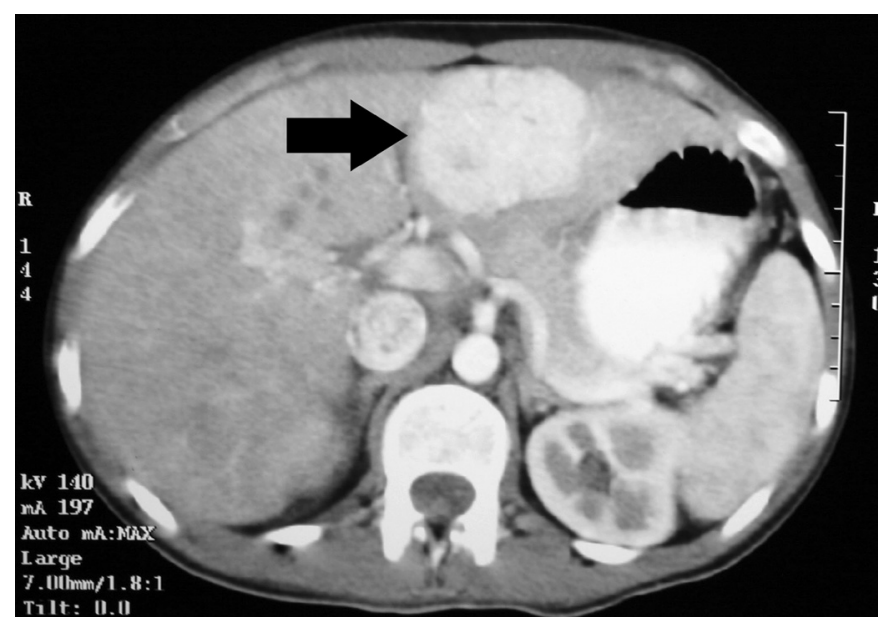

Fig. 1. Tomografía computerizada abdominal tras la inyección de contraste intravenoso: captación importante de la masa hepática.

La biopsia de la masa confirmó el diagnóstico de HNF, mostrando cómo los hepatocitos conservaban la disposición trabecular, sin presencia de atipias significativas, colestasis ni acumulación anormal de pigmentos. En algunas zonas los hepatocitos se agrupaban más densamente, con un aspecto vagamente nodular que parecía comprimir las zonas periféricas. En revisiones posteriores el tamaño de la lesión se mantuvo estable.

La aparición sincrónica de HNF y adenomas hepáticos descrita en ocasiones, ha llevado a sugerir posibles causas comunes para ambas: desde anomalías angiogénicas inducidas por anticonceptivos orales, hasta trombosis y shunts arteriovenosos por factores de crecimiento estimulantes de tumores (5). Su lesión típica consiste en una masa de nódulos de hepatocitos normales con focos de proliferación ductal biliar intranodular separados por bandas fibrosas. Una arteria solitaria con alto flujo sanguíneo da a la masa la apariencia radiológica de una región fibrosa estrellada central que contiene estructuras vasculares malformadas con grandes arterias pero sin venas portales $(3,4)$.

La HNF es una lesión benigna habitualmente asintomática cuyo tamaño suele permanecer estable (6). A menudo se trata, como en este caso, de un hallazgo casual, que rara vez produce dolor abdominal recurrente o colestasis por compresión de la vía biliar $(2,4)$. Es especialmente importante el diagnóstico diferencial con el hepatocarcinoma fibrolamelar (HCF), ya que ambos suelen aparecer en jóvenes sin cirrosis y tienen una cicatriz central en las pruebas de imagen (7). La HNF es isodensa respecto al hígado en TC, excepto en imágenes en fase arterial tras la inyección de contraste, en las que aparece un realce homogéneo pronunciado que la distingue de hemangiomas y metástasis $(7,8)$. Sin embargo, variaciones en la densidad o hallazgos de imagen atípicos están presentes en cerca del $50 \%$ de los pacientes con HNF; en estos casos, la RM podría ser útil, mostrando en el $78 \%$ de los casos una cicatriz que característicamente se realza intensamente en T2 y mínimamente en T1, a diferencia del HCF, en el que si hay cicatriz ésta suele ser hipointensa $(7,9)$.

En pacientes asintomáticos con HNF se puede adoptar una actitud conservadora y efectuar un seguimiento de las lesiones. La cirugía está reservada para pacientes sintomáticos, habitualmente con abdominalgia o colestasis, o bien cuando el diagnóstico diferencial, especialmente con el adenoma, no está claro (2).

\section{J. I. Martín-Serradilla, M. A. Tejero Delgado, I. García Mar- tínez ${ }^{1}$, S. Franco Hidalgo, E. Laherrán Rodríguez}

Servicios de Medicina Interna y ${ }^{\prime}$ Digestivo. Hospital General Río Carrión. Palencia

1. Chicano Marín FJ, Torroba Carón A, Aranda García MJ, Ruiz Jiménez JI, Jiménez Abadía MA. Hiperplasia nodular focal hepática. A propósito de un caso. An Esp Pediatr 2000; 52: 279-80.

2. Carrasco Torrens R, Castañón García-Alix M, San Vicente Vela B, Montaner Brunat A, Morales Fochs L. Hiperplasia nodular focal del hígado. An Esp Pediatr 2001; 55: 569-72.

3. Lepreux S, Laurent C, Balabaud C, Bioulac-Sage P. FNH-like nodules: possible precursor lesions in patients with nodular hyperplasia $(\mathrm{FNH})$. Comp Hepatol 2003; 2: 7 .

4. Ji Y, Zhu X, Sun H, et al. Hepatocellular adenoma and focal nodular hyperplasia: a series of 24 patients with clinicopathological and radiological correlation. Chin Med J (Engl) 2000; 113: 852-7.

5. Laurent C, Trillaud H, Lepreux S, Balabaud C, Bioulac-Sage P. Association of adenoma and focal nodular hyperplasia: experience of a single French academic center. Comp Hepatol 2003; 2: 6.

6. D'halluin V, Vilgrain V, Pelletier G, et al. Evolution naturelle de l'hyperplasie nodulaire focale. Etude rétrospective de 44 cas. Gastroenterol Clin Biol 2001; 25: 1008-10.

7. McLarney JK, Rucker PT, Bender GN, Goodman ZD, Kashitani N, Ros PR. Fibrolamellar carcinoma of the liver: radiologic-pathologic correlation. Radiographics 1999; 19: 453-71.

8. Nino-Murcia M, Olcott EW, Brooke Jeffrey R, Lamm RL, Beaulieu C F, Jain KJ. Focal liver lesions: pattern-based classification scheme for enhancement at arterial phase CT. Radiology 2000; 215: 746-51-

9. Ko K R, Lee D H, Park J S, et al. Focal nodular hyperplasia with retraction of liver capsule: a case report. Korean J Radiol 2003; 4: 66-9. 